\title{
Projeto de um Gateway para Automação Residencial
}

\author{
Title: Design of a gateway for home automation
}

Tiago José de Araújo Ribeiro

Escola Politécnica de Pernambuco

Universidade de Pernambuco

50.720-001 - Recife, Brasil

tj_ribeiro@yahoo.com.br

\author{
Sérgio Campello Oliveira \\ Escola Politécnica de Pernambuco \\ Universidade de Pernambuco \\ 50.720-001 - Recife, Brasil \\ scampello@ecomp.poli.br
}

Resumo Anternet das Coisas tem possibilitado novas experiências de uso e formas de interação com os
dispositivos ao nosso redor. Embora tenha havido muito avanço em conectividade, os aparelhos
domésticos ainda encontram-se em fase de transição para uma arquitetura totalmente conecta-
da. Aparelhos legados sem conectividade ainda estão presentes no mercado e nas residências e
contam com alguns anos ainda de sobrevida. Nas últimas décadas novas tecnologias foram
lançadas e introduzidas no ambiente doméstico, aumentando o número de aparelhos. Apesar de
esforços para a uniformização dos meios e protocolos dos controles remotos, diferentes padrões
foram adotados por fabricantes ou grupos de fabricantes, resultando na presença de controles
remotos específicos para cada aparelho. Este trabalho aborda os problemas de convergência de
controle dos aparelhos e a conectividade dos aparelhos domésticos, desenvolvendo um protóti-
po de um gateway para automação residencial que concentre tecnologias de transmissão de
dados e controle de dispositivos em um ambiente residencial. O dispositivo tem por finalidade
agir como uma ponte entre um smartphone e dispositivos eletroeletrônicos através de uma rede
sem fio IEEE 802.11, podendo ser acessado de qualquer lugar por meio da conexão dessa rede
à Internet. Através de interfaces de transmissão e recepção de sinais infravermelhos (infrared-
IR) e em radiofrequência (RF) de $433 \mathrm{MHz}$ é possivel controlar aparelhos de entretenimento e
automação residencial.

Palavras-Chave: automação residencial, Internet das Coisas (IoT), eletrônicos de consumo

\begin{abstract}
The Internet of Things has enabled new user experiences and forms of interaction with the devices around us. Although there has been much advancement in connectivity, household appliances are still in transition to a fully connected architecture. Legacy devices without connectivity are still present in the market and in homes and have some more years of survival. In recent decades new technologies were launched and introduced in the household, increasing the number of devices. Despite efforts to standardize the means and protocols of the remote controls, different standards have been adopted by manufacturers or groups of manufacturers, resulting in the presence of specific remotes for each device. This work deals with the problems of convergence of devices control and home appliances connectivity, developing a prototype of a gateway for home automation that concentrates data transmission and devices control technologies in a residential environment. The device is intended to act as a bridge between a smartphone and consumer electronics devices via a wireless IEEE 802.11 network and can be accessed from anywhere through this network Internet connection. Through transmission interfaces and reception of infrared signals (infrared - IR) and radio frequency (RF) of $433 \mathrm{MHz} c a n$ be controlled entertainment appliances and home automation.
\end{abstract}

Keywords: home automation, Internet of Things (IoT), consumer electronics 


\section{Introdução}

A Internet tem mudado continuamente a forma com que as pessoas se relacionam entre si e, mais recentemente, com o advento da Internet das Coisas (Internet of Things - IoT), tem mudado também a forma com que as pessoas interagem com os dispositivos. A Internet das Coisas pode ser entendida como a expansão dos serviços de Internet a partir da interação entre pessoas e dispositivos e entre dispositivos [1].

Inicialmente concebida para a troca de dados entre computadores, a Internet foi levada para os computadores portáteis, para os assistentes pessoais digitais (Personal Digital Assistants - PDAs), para os celulares e para os smartphones, estes últimos com poder de processamento muitas vezes superior ao dos primeiros computadores conectados à rede. Embora várias aplicações foram propostas desde o nascimento da Internet [2], é possível afirmar que as primeiras Coisas da Internet das Coisas foram realmente os smartphones por sua presença ubíqua. Não demorou para que outros dispositivos e eletrônicos de consumo pudessem ser conectados à Internet (como Smart TVs e receptores de serviços de TV por assinatura) e outros dispositivos surgissem a partir dessa possibilidade, como por exemplo, AppleTV $\AA$ e Chromecast ${ }^{\circledR}$.

Embora tenha havido muito avanço na conectividade de dispositivos eletrônicos de consumo, de maneira geral estes ainda encontram-se em fase de transição para uma arquitetura completamente conectada [3,4], de modo que usam serviços da rede mas ainda são controlados ou iniciados por seu controle remoto específico. Aparelhos antigos sem qualquer forma de conexão ainda contam com uma sobrevida de alguns anos até que sejam completamente substituídos pelos aparelhos conectados.

Durante as últimas décadas foi possível observar a introdução crescente de novas tecnologias e, com estas, novos aparelhos no ambiente doméstico com o objetivo de prover maior conforto, reduzir o esforço em tarefas domésticas e ampliar as possibilidades de entretenimento. Controlar dispositivos elétricos e eletrônicos remotamente tem se tornado uma ação cada vez mais presente tanto em ambientes industriais quanto comerciais ou domésticos. No caso dos aparelhos eletroeletrônicos de consumo, embora tenha havido esforços no sentido de uniformizar os meios e protocolos de controles remotos, diferentes padrões foram adotados por fabricantes ou grupos de fabricantes [5].

A primeira geração de controles remotos universais foi baseada em alguns dos protocolos de comunicação infravermelho (infrared - IR) adotados como padrão da indústria de eletrônicos de consumo. Estes possuem os códigos de comandos comuns de diversos fabricantes armazenados em uma memória fixa podendo não ser utilizável com todos os aparelhos presentes no mercado em determinado momento ou com aparelhos lançados no futuro. Controles remotos universais mais modernos são mais flexíveis e podem ser personalizados. Alguns modelos podem conectar-se à rede sem fio e à Internet propondo-se a substituir os demais controles remotos do ambiente. Ainda assim, é um dispositivo específico para controle de aparelhos via IR que demanda que o usuário o tenha sempre em mãos.

É possível encontrar hoje no mercado aparelhos muitas vezes denominados gateways para automação residencial, que se propõem a atuarem como controles universais. Sua interface com o usuário é normalmente através de um aplicativo instalado em um smartphone comunicando-se com o gateway por uma rede local ou mesmo pela Internet e enviando os comandos que são interpretados e repassados pelo gateway para o dispositivo. A Figura 1 apresenta a arquitetura de um gateway para automação residencial.

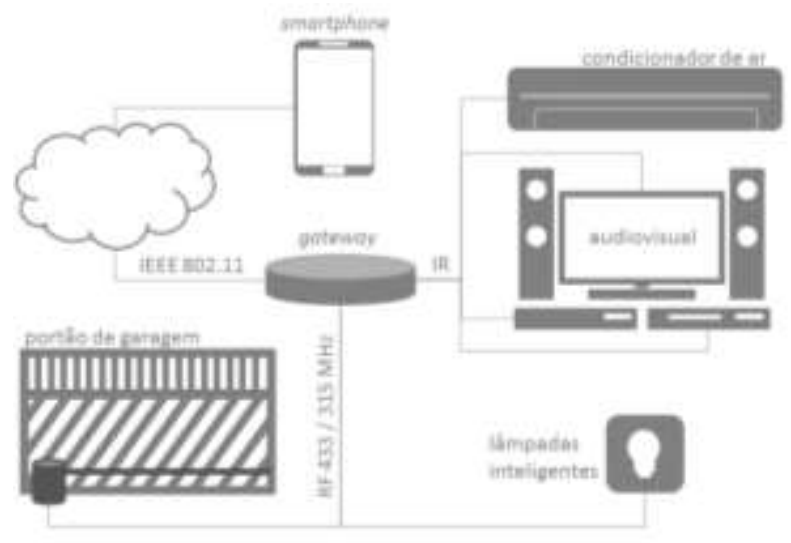

Figura 1: Arquitetura de um gateway para automação residencial.

Os principais problemas a serem abordados neste trabalho são convergência de controle e conectividade de aparelhos domésticos. Embora controles remotos universais sejam uma alternativa para a convergência, normalmente não resolvem o problema de conectividade. Os gateways presentes no mercado normalmente possuem custos altos ou são específicos para uma família de dispositivos.

O presente trabalho se propõe a desenvolver o protótipo de um dispositivo (gateway) que possa concentrar as tecnologias de transmissão de dados e controle de dispositivos domésticos e agir como uma ponte entre um smartphone e dispositivos eletroeletrônicos através de uma rede sem fio IEEE 802.11, podendo ser acessado de qualquer lugar por meio da conexão dessa rede à Internet. Pretende-se que o dispositivo possa ser usado para controlar de maneira mais simples outros dispositivos de automação residencial como: portões automatizados, 
fechaduras eletrônicas, lâmpadas, centrais de alarme e monitoramento, entre outros. $\mathrm{O}$ aplicativo no celular pode permitir o controle inteligente e individualizado. Pode se comunicar com outros aplicativos de controle para automação residencial, aumentando a potencialidade do sistema.

\section{Projeto de hardware}

Como requisitos mínimos, o dispositivo proposto para atuar como um gateway deverá possuir interface para emissão e recepção (decodificação) de sinais em IR a fim de interagir com os aparelhos eletroeletrônicos que possuem controle remoto. Deverá ser capaz também de emitir e receber sinais de rádio nas frequências mais comumente utilizadas para o acionamento de dispositivos de automação residencial $(433 / 315 \mathrm{MHz})$. Um sensor de temperatura deverá ser integrado ao dispositivo, possibilitando futuras adaptações para a inclusão de outros sensores no sistema.

Será necessária a implementação de comunicação em rede sem fio IEEE 802.11 para que o dispositivo se comunique com sua interface com o usuário, sendo esta $o$ aplicativo instalado no smartphone do usuário.

Um diagrama de blocos do gateway é mostrado na Figura 2 e apresenta os componentes do sistema e suas interligações.

\subsection{Plataforma de prototipação rápida}

Como processador e controlador de periféricos optouse por usar a plataforma Arduino ${ }^{\circledR}$, por sua facilidade de uso para prototipação rápida e prova de conceito, além da grande quantidade de bibliotecas e informação gerada pela comunidade de usuários. A versão utilizada foi a
Nano, que possui tamanho reduzido comparado ao da versão mais popular Uno, disponibilidade no mercado e um microcontrolador Atmel ${ }^{\circledR}$ ATMega 328P de 8 bits e arquitetura RISC. Outra vantagem é que o código gerado pelo ambiente de desenvolvimento integrado (Integrated Development Environment - IDE) do Arduino pode ser utilizado diretamente no microcontrolador.

\subsection{Infravermelho para aparelhos eletrônicos de consumo}

O espectro de luz infravermelha tem sido usado desde os primeiros aparelhos domésticos com controle remoto e ainda é amplamente utilizado por sua simplicidade e baixo custo para aplicações onde normalmente há visada direta e proximidade suficiente entre o usuário e o dispositivo a ser controlado.

Para garantir que a informação chegue ao receptor e seja interpretada corretamente, o sinal é modulado e codificado pelo emissor, devendo o receptor demodular e decodificar o sinal recebido. Sistemas de controle remoto normalmente usam Modulação por Código de Pulso (Pulse Code Modulation - PCM), com uma frequência de portadora entre $30 \mathrm{kHz}$ e $58 \mathrm{kHz}$ [6]. Dentre os esquemas de codificação destacam-se a codificação por distância de pulso, a codificação por comprimento de pulso e a codificação Manchester, sendo a primeira a mais utilizada.

Enquanto alguns fabricantes de aparelhos eletrônicos criaram seus próprios protocolos, outros seguiram os existentes, configurando um conjunto de protocolos que se tornaram padrão de indústria, entre os quais destacamse o NEC, o Philips RC5 e RC6 e o Sony. A Figura 3 ilustra a forma de onda do protocolo NEC.

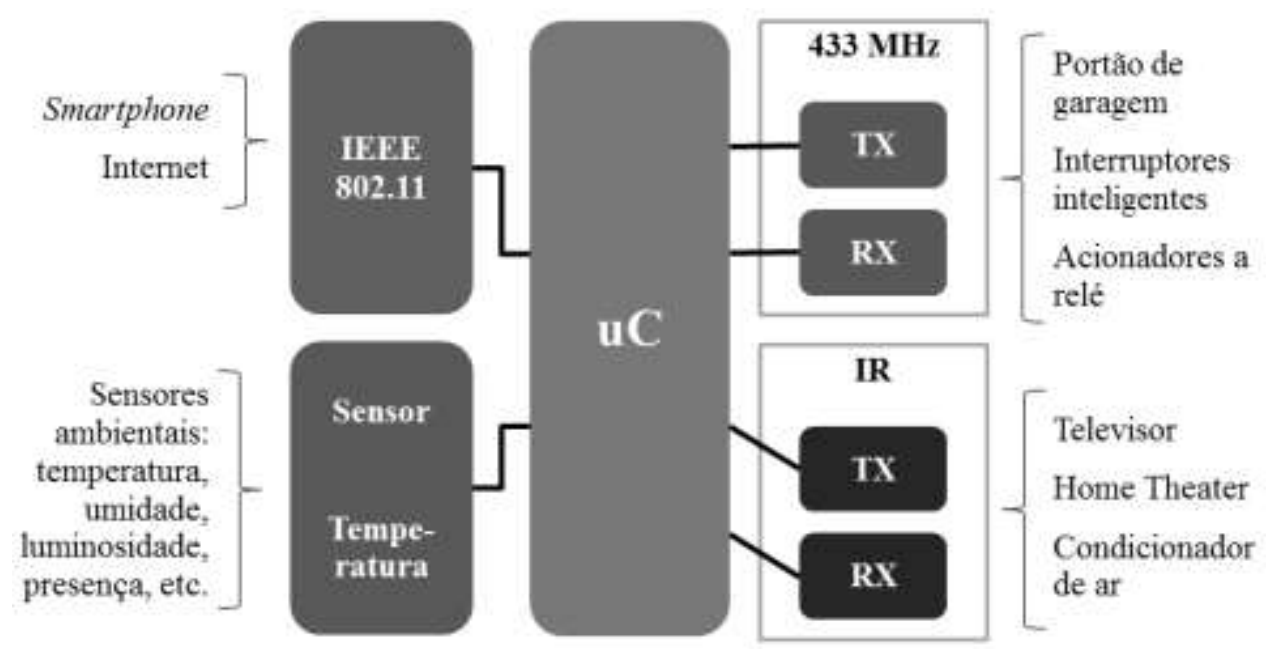

Figura 2: Diagrama de blocos do gateway para automação residencial. 


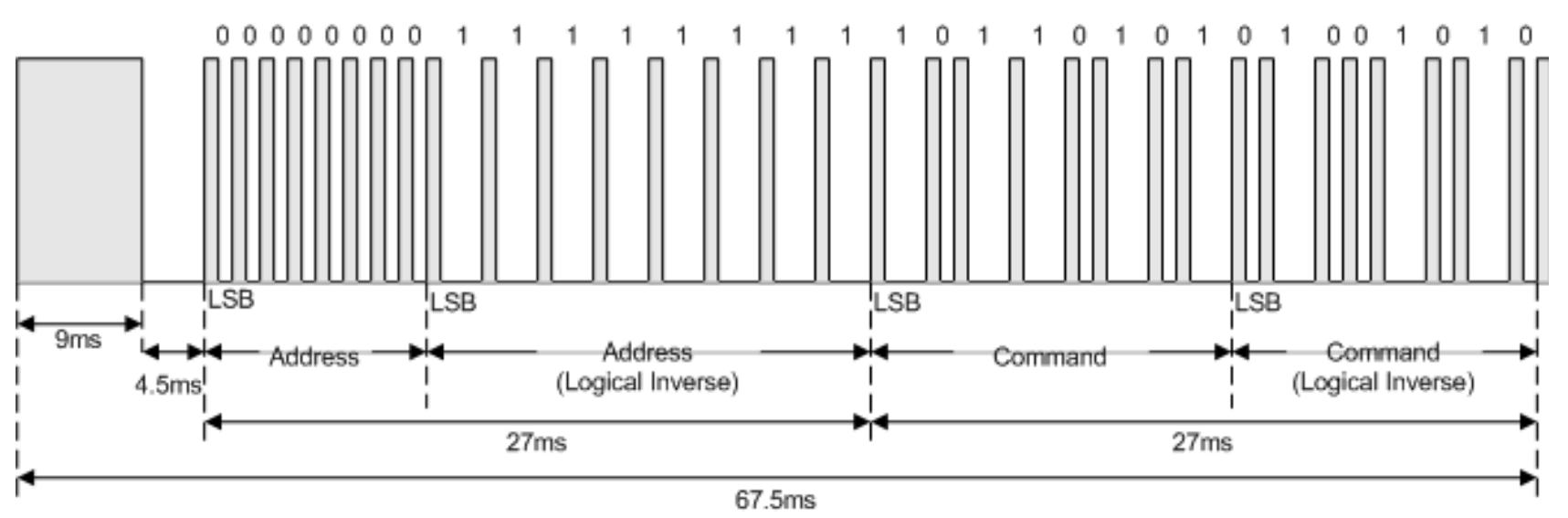

Figura 3: Exemplo de forma de onda de um comando seguindo o protocolo NEC [7].

Um LED IR foi usado para emitir os pulsos da portadora, sendo acionado através de um circuito simples composto por um transistor bipolar de junção do tipo NPN e um resistor. Foi usado um resistor de $100 \mathrm{Ohms}$, gerando uma corrente de $43 \mathrm{~mA}$ no LED, acima da nominal (cerca de $30 \mathrm{~mA}$ ), implicando maior potência luminosa, mas por um curto intervalo de tempo (período em estado alto da onda portadora), fazendo com que a potência dissipada esteja dentro dos limites dos componentes.

Um receptor IR TSOP1838 foi utilizado para receber e demodular os comandos vindos de um controle remoto para que sejam decodificados e armazenados. O receptor IR possui um componente sensível à luz infravermelha (fototransistor ou fotodiodo) e um circuito de demodulação que filtra os sinais luminosos espúrios no espectro de luz infravermelha (iluminação ambiente), apresentando em seu terminal de saída os sinais de marcas e espaços presentes na portadora.

\subsection{Transmissão e recepção em RF $433 \mathrm{MHz}$}

Alguns dos dispositivos de automação residencial funcionam com controles remotos que utilizam radiofrequência de 433 ou $315 \mathrm{MHz}$, normalmente em modulação por chaveamento de amplitude (amplitude shift keying - ASK) com apenas dois níveis, chamada de chaveamento liga-desliga (on-off keying - OOK).

Desses dispositivos, os mais comumente presentes são os automatizadores de portões de garagem. Apesar de estarem sendo substituídos por codificadores de código rolante (rolling code), ainda estão presentes no mercado automatizadores que usam circuitos integrados codificadores de código fixo, sendo o codificador HT6P20B o mais comumente encontrado nesses dispositivos. Existem ainda no mercado pequenos dispositivos baseados no mesmo codificador que se propõem a acionar uma carga qualquer via relé.
A decodificação e posterior reprodução do código fixo baseado no HT6P20B foram implementadas como prova de conceito e, para isso, foi utilizado um módulo transmissor e um módulo receptor em $433 \mathrm{MHz}$ com modulação ASK-OOK (Figura 4).
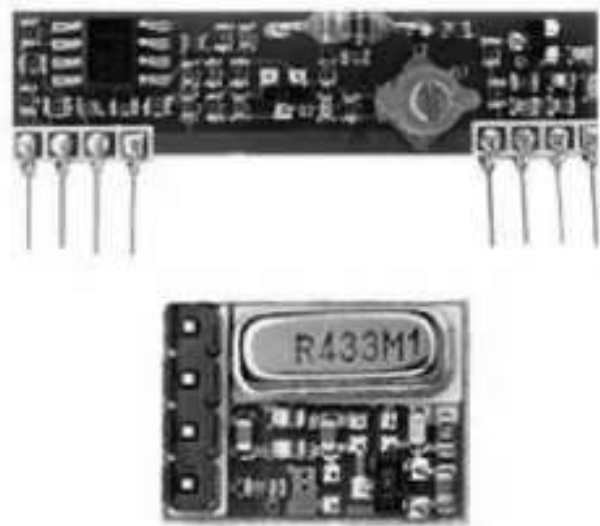

Figura 4: Módulos receptor e transmissor de rádio em 433 MHz.

\subsection{Sensores ambientais}

Para o presente trabalho, foi incluído um sensor de temperatura LM35, com o propósito de informar ao usuário, tomar ações automáticas baseadas na leitura do sensor (controlar o aparelho de ar-condicionado) e servir como prova de conceito para a posterior inclusão de outros tipos de sensores, como sensores de umidade, luminosidade, presença, etc.

\subsection{Interface com rede sem fio IEEE 802.11}

Foi utilizado, para a interface com a rede sem fio IEEE 802.11, um módulo baseado no sistema integrado em um chip (System-on-Chip - SoC) ESP8266 da Espressif. O SoC contém um processador de 32 bits, camada física do padrão IEEE 802.11 implementada em hardware e periféricos para entradas e saídas digitais, entrada 
analógica e barramentos de comunicação. O módulo ESP-01 utilizado possui pequeno formato e integra, além do SoC, uma memória do tipo flash de 1 MB para armazenamento do firmware e dados. O módulo é mostrado na Figura 5.

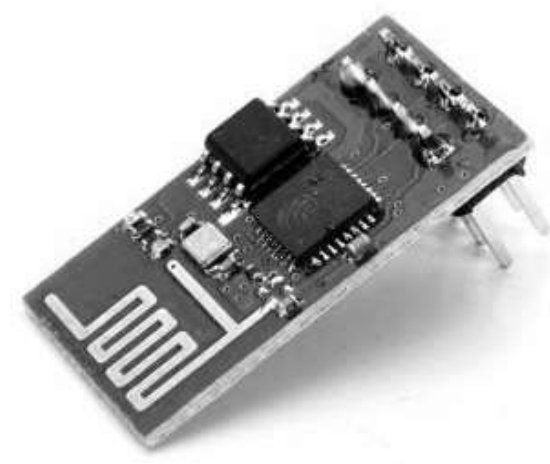

Figura 5: Módulo ESP-01 para interface com rede IEEE 802.11.

\section{Desenvolvimento do Firmware}

O firmware foi desenvolvido usando o ambiente de desenvolvimento integrado (Integrated Development Environment - IDE) do Arduino ${ }^{\circledR}$. Buscou-se utilizar bibliotecas desenvolvidas pela comunidade e as mais comumente utilizadas.

A interface entre o Arduino ${ }^{\circledR}$ e o módulo ESP8266 é feita através de uma comunicação serial, sendo que o Arduino ${ }^{\circledR}$ aguarda um comando para executar uma ação ou responder com alguma informação. Para essa finalidade, optou-se por utilizar a biblioteca CmdMessenger [8], que implementa uma interface de linha de comando (command line interface-CLI).

A biblioteca IRremote [9] implementa as funções de decodificação e envio dos códigos de comandos IR. A função de decodificação monitora uma entrada digital e identifica uma marca (mark) ou um espaço (space), decodificando o sinal recebido em zeros e uns com base no tempo de cada estado. No envio do código, a biblioteca faz uso do periférico de modulação em largura de pulso (pulse width modulation - PWM) nativo do microcontrolador, cujo período e ciclo de trabalho são configurados para gerar um sinal na frequência da portadora. $\mathrm{O}$ sinal do código IR é obtido ao habilitar e desabilitar a saída do PWM em uma saída digital ligada ao circuito de excitação do LED IR.

$\mathrm{O}$ algoritmo de decodificação dos códigos transmitidos em RF $433 \mathrm{MHz}$ no padrão do codificador HT6P20B foi baseado em seu datasheet [10] e sua ideia de funcionamento é semelhante à da decodificação dos códigos IR. A transmissão é baseada somente no acionamento de uma saída digital ligada ao módulo transmissor.
O ESP8266 é normalmente vendido com uma versão de firmware que recebe comandos no padrão AT. Optouse por usar, no entanto, o firmware NodeMCU, que possui interface com o usuário mais amigável e permite a execução de scripts escritos na linguagem Lua.

\subsection{Configuração de acesso à rede local}

No primeiro uso do gateway, o módulo ESP8266 não está conectado a nenhuma rede sem fio e se comporta como ponto de acesso (access point - AP), permitindo que o usuário se conecte a ele pelo smartphone e forneça o nome e a chave de acesso da rede sem fio residencial. $\mathrm{O}$ módulo ESP8266 passa a funcionar então no modo estação (station - STA) e desativa o modo AP. A partir desse momento, tanto o smartphone quanto o gateway estão na mesma rede e podem se comunicar entre si e com outros dispositivos que estejam na rede. O fluxograma desse processo é apresentado na Figura 6.

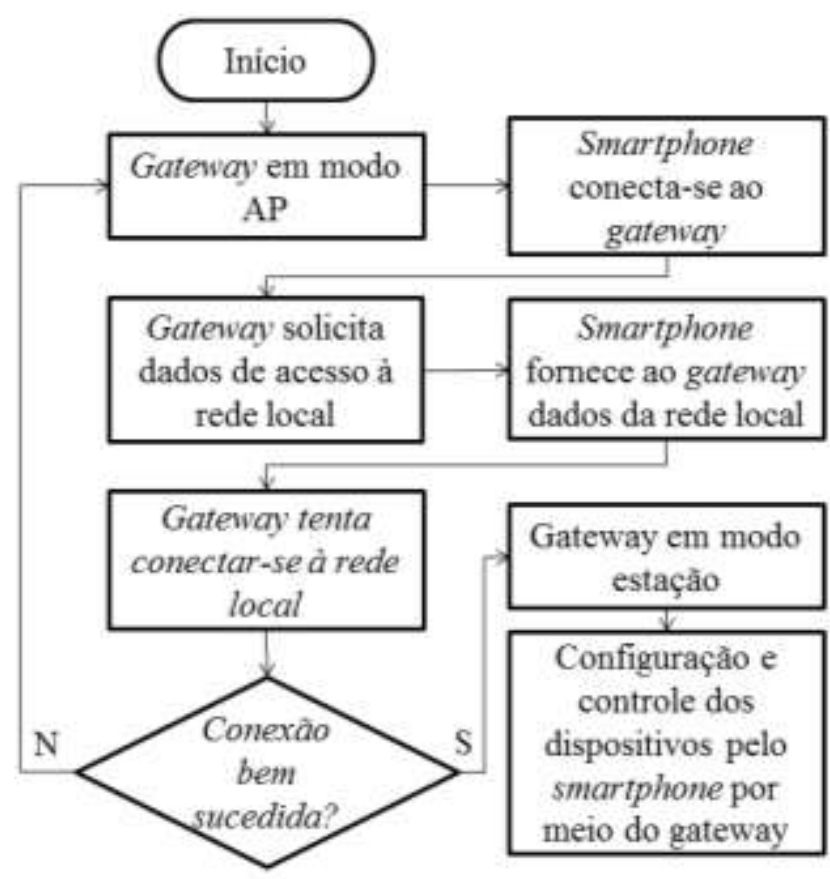

Figura 6: Fluxograma de configuração de acesso.

\section{Resultados}

Um protótipo foi produzido integrando e interligando os módulos. A Figura 7 apresenta uma foto do protótipo montado em uma matriz de contatos. Estão destacadas as interfaces de transmissão e recepção em IR e RF, bem como o sensor de temperatura, o módulo IEEE 802.11 e o Arduino. A alimentação do circuito é realizada por meio da interface USB do Arduino e regulada para 3,3 V para alimentar o módulo ESP8266. 


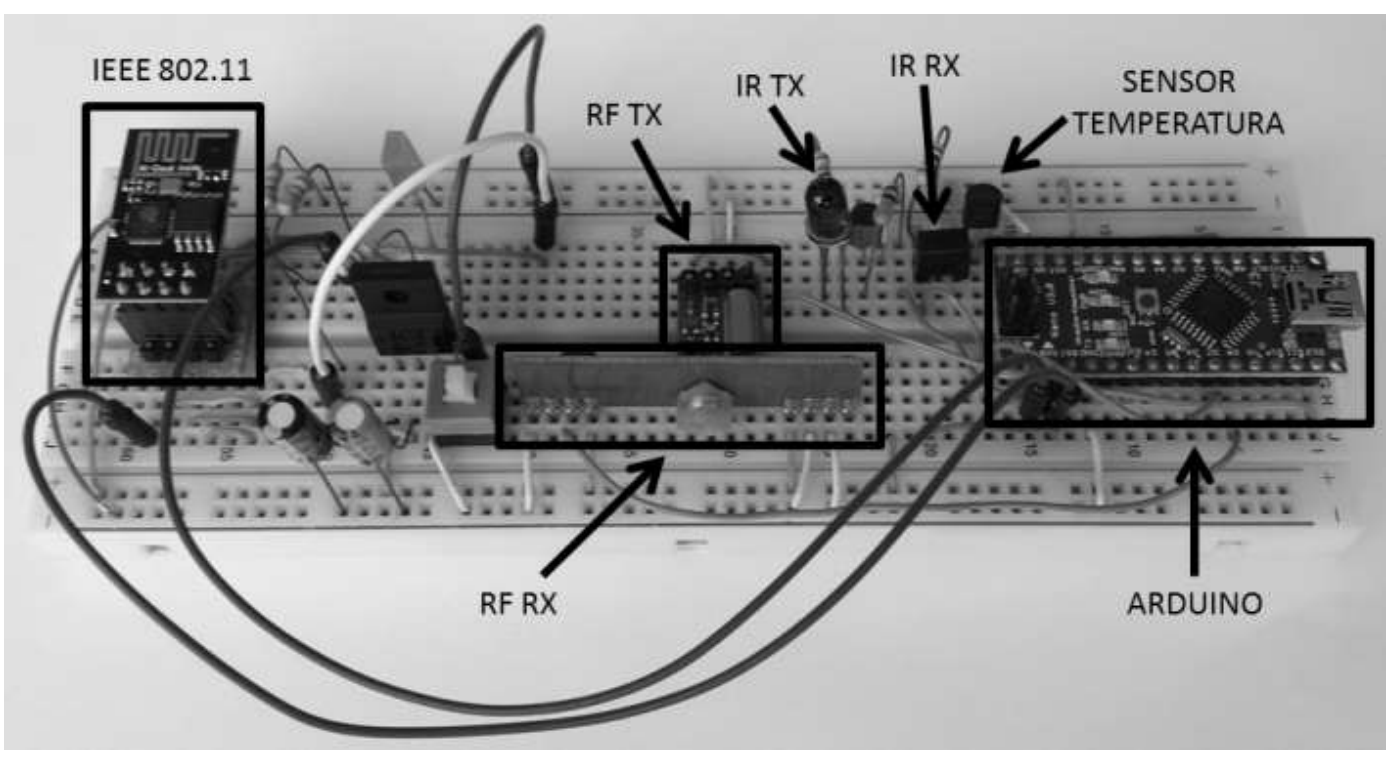

Figura 7: Protótipo do gateway implementado em matriz de contatos.

Foi desenvolvido um aplicativo para smart-phones usando a plataforma Android ${ }^{\circledR}$ com interface simples para prova de conceito. O aplicativo implementa, juntamente com o módulo ESP8266, as ações presentes no fluxograma da Figura 6 e é capaz de enviar comandos fixos e armazenar os códigos recebidos e decodificados pelo gateway.

A Figura 8-a mostra a tela de configuração de acesso do gateway. Ao acionar o botão "SCAN", o aplicativo busca uma rede sem fio com um SSID específico. Existem campos para que sejam fornecidas as informações de acesso à rede local. Ao acionar o botão "CONNECT" dáse início ao processo de configuração e conexão, no qual as informações de acesso são fornecidas ao gateway.

Uma vez que o gateway encontra-se conectado e acessível na rede local, a tela de comandos é exibida (Figura 8-b). Nela são listados os comandos cadastrados e, ao clicar em um deles, o comando é enviado para o gateway.

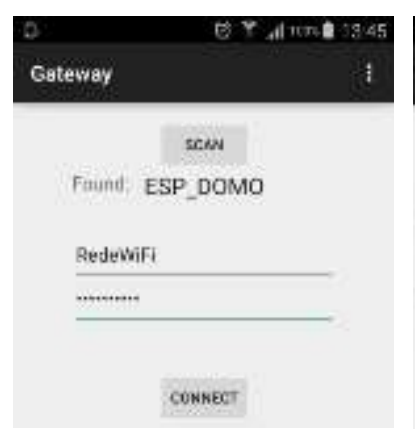

(a)

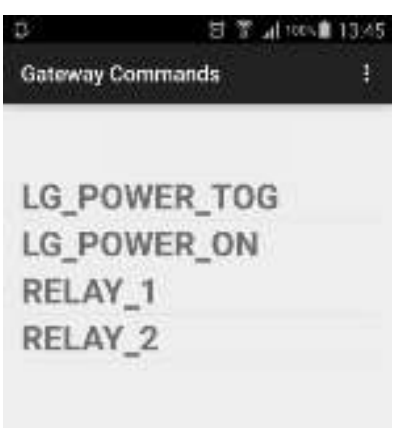

(b)
Figura 8: Telas do aplicativo: tela de configuração de acesso (a) e tela de comandos (b).
Foram realizados testes do protocolo de configuração e conexão com sucesso. Testes de envio de comandos e recebimento de códigos IR foram realizados com sucesso para controlar aparelhos como TVs, DVDs e Home Theaters. Aparelhos de ar condicionado não foram incluídos nos testes. Testes foram conduzidos com sucesso também para controlar acionadores de portões de garagem baseados no codificador HT6P20B e, acionadores de propósito geral a relé.

Verificou-se experimentalmente que o gateway deve estar localizado preferencialmente em posição central no cômodo devendo possuir visada direta em relação aos dispositivos que se deseja controlar via IR. Deve-se procurar afastar o dispositivo de fontes de calor para que não haja diferenças entre o valor de temperatura obtido pelo sensor e a temperatura real no ambiente.

Uma demonstração do funcionamento para controle de dispositivos via IR e RF pode ser vista no vídeo publicado em [11].

\section{Conclusão e trabalhos futuros}

O projeto realizado atende aos requisitos propostos de convergência, proporcionando aos usuários o controle centralizado de diversos dispositivos presentes em uma residência. Atende ainda ao requisito de conectividade, permitindo o controle remoto através da Internet, sem a necessidade de estar no mesmo ambiente, como é o caso de controles remotos IR que requerem visada direta e os controles remotos RF, que requerem que o usuário esteja no raio de alcance do sinal.

A tendência é que no futuro a maioria dos dispositivos domésticos estejam totalmente conectados à Internet das 
Coisas e que haja alguma padronização. Outro objetivo alcançado com o gateway para automação residencial é a inserção de dispositivos antigos no contexto da Internet das Coisas. Não será necessário o descarte de produtos desconectados com vida útil pela frente nem esperar que a indústria lance produtos totalmente conectados.

No caso real de uso de um gateway para automação residencial, devem ser observados aspectos relativos a segurança. A adoção da codificação rolante em detrimento da codificação fixa, por questões de segurança, tende a eliminar do mercado os dispositivos de codificação fixa. Embora o uso de codificação rolante diminua drasticamente o risco de emulação do código esperado pelo receptor, uma rede com esquema de segurança frágil pode ser um ponto de acesso para que indivíduos não autorizados controlem cargas e equipamentos que podem incluir controles de acesso à residência. Possíveis métodos de ataque e aspectos de segurança de rede são expostos em [12].

A captura e envio de códigos de acionadores de portões foi implementada com sucesso. Tendo em vista os aspectos de segurança mencionados, uma extensão deste trabalho poderá incluir codificação rolante compatível com acionadores presentes no mercado e esquemas de segurança de rede para acesso por meio da Internet.

Como sequencia para o presente trabalho poderia ser incluída uma interface de RF em $315 \mathrm{MHz}$, outra frequência de uso comum para acionamento de dispositivos de automação residencial. Outras possibilidades são a inclusão de uma interface Bluetooth, o desenvolvimento de módulos remotos para acionamento de cargas e feedback, a produção de uma placa de circuito impresso, bem como prover a interação com outros sistemas de automação residencial e segurança eletrônica. Pode ser necessário também desenvolver códigos que substituam as bibliotecas utilizadas no protótipo para se adequar às necessidades do projeto e eliminar a dependência das licenças.

Apesar de existirem soluções semelhantes já disponíveis comercialmente, o dispositivo desenvolvido servirá como base para facilmente expandir suas capacidades e será uma plataforma sobre a qual podem ser implementadas e testadas soluções propostas como padrão para a Internet das Coisas.

\section{Referências}

[1] G. Tripathi, D. Singh, A. J. Jara. A survey of Internet-of-Things: Future Vision, Architecture, Challenges and Service. IEEE World Forum on Internet of Things (WF-IoT), páginas 287-292, 2014.
[2] J. V. Daniel, P. Suresh, R. H. Aswathy, V. Parthasarathy. A state of the art review on the Internet of Things (IoT): History, Technology and fields of deployment. International Conference on Science Engineering and Management Research (ICSEMR), páginas 1-8, 2014.

[3] K. Bing, L. Fu, Y. Zhuo, L. Yanlei. Design of an Internet of Things-based Smart Home System. $2^{\text {nd }}$ International Conference on Intelligent Control and Information Processing, páginas 921924, IEEE, 2011.

[4] V. Miori, D. Russo. Domotic evolution towards the IoT. 28th International Conference on Advanced Information Networking and Applications Workshops. páginas 809-814, IEEE, 2014.

[5] J. Sathyan, A. R. Ramakrishnan. A Unique SelfContained Universal Remote Control. IEEE Transactions on Consumer Electronics. 50(4):1151-1155, IEEE, 2004.

[6] Infrared Communication Concepts. http://techdocs.altium.com/display/FPGA/Infrare d+Communication+Concepts, Nov. 2015.

[7] NEC Infrared Transmission Protocol. http://techdocs.altium.com/display/FPGA/NEC+ Infrared+Transmission+Protocol, Nov. 2015.

[8] T. Elenbaas. CmdMessenger Library http://playground.arduino.cc/Code/CmdMesseng er, Nov. 2015.

[9] K. Shirriff. IRremote Arduino Library. https://github.com/z3t0/Arduino-IRremote, Nov. 2015.

[10] HOLTEK. HT6P20X Series $2^{24}$ OTP Encoder. http://www.holtek.com/pdf/consumer/6p20v170. pdf, Nov. 2015.

[11] T. Ribeiro. Gateway para automação residencial. https://www.youtube.com/watch?v=I2YvNX4A QjU, Dez. 2015.

[12] J. Margulies. Garage Door Openers: An Internet of Things Case Study. IEEE Security \& Privacy Magazine. 13(4):80-83, IEEE, 2015. 